\title{
The Nrf2/ARE Pathway: A Promising Target to Counteract Mitochondrial Dysfunction in Parkinson's Disease
}

\author{
Kemal Ugur Tufekci, Ezgi Civi Bayin, Sermin Genc, and Kursad Genc \\ Department of Neuroscience, Health Science Institute, Dokuz Eylul University, Inciralti, 35340 Izmir, Turkey \\ Correspondence should be addressed to Kemal Ugur Tufekci, ugurtufekci@gmail.com
}

Received 30 September 2010; Revised 25 November 2010; Accepted 3 January 2011

Academic Editor: Charleen T. Chu

Copyright (๑) 2011 Kemal Ugur Tufekci et al. This is an open access article distributed under the Creative Commons Attribution License, which permits unrestricted use, distribution, and reproduction in any medium, provided the original work is properly cited.

\begin{abstract}
Mitochondrial dysfunction is a prominent feature of various neurodegenerative diseases as strict regulation of integrated mitochondrial functions is essential for neuronal signaling, plasticity, and transmitter release. Many lines of evidence suggest that mitochondrial dysfunction plays a central role in the pathogenesis of Parkinson's disease (PD). Several PDassociated genes interface with mitochondrial dynamics regulating the structure and function of the mitochondrial network. Mitochondrial dysfunction can induce neuron death through a plethora of mechanisms. Both mitochondrial dysfunction and neuroinflammation, a common denominator of $\mathrm{PD}$, lead to an increased production of reactive oxygen species, which are detrimental to neurons. The transcription factor nuclear factor E2-related factor 2 (Nrf2, NFE2L2) is an emerging target to counteract mitochondrial dysfunction and its consequences in PD. Nrf2 activates the antioxidant response element (ARE) pathway, including a battery of cytoprotective genes such as antioxidants and anti-inflammatory genes and several transcription factors involved in mitochondrial biogenesis. Here, the current knowledge about the role of mitochondrial dysfunction in PD, Nrf2/ARE stress-response mechanisms, and the evidence for specific links between this pathway and PD are summarized. The neuroprotection of nigral dopaminergic neurons by the activation of Nrf2 through several inducers in PD is also emphasized as a promising therapeutic approach.
\end{abstract}

\section{Introduction}

Parkinson's disease (PD) is a prevalent and progressive neurodegenerative incurable movement disorder. The disease is characterized by the loss of dopaminergic neurons in the substantia nigra pars compacta $(\mathrm{SNpc})$ and the presence of proteinaceous deposits within neuronal perikarya (Lewy bodies) and processes (Lewy neurites). These deposits are composed of $\alpha$-synuclein, ubiquitin, neurofilaments, and molecular chaperones [1]. Nigral dopaminergic neuron death leads to a deficiency of the neurotransmitter dopamine in the striatum and consequent dysregulation of basal ganglia circuitries accounting for motor symptoms of bradykinesia, hypokinesia, progressive rigidity, resting tremor, and postural instability. Lewy body deposition is also associated with nonmotor features such as autonomic dysfunction, sleep disturbances, depression, and cognitive impairment $[1,2]$. A major risk factor is aging, as in other neurodegenerative diseases, although people with the familial monogenic forms of the disease can present before 45 years of age [1]. Since the sporadic and monogenic forms of PD share important clinical, pathological, and biochemical features, notably the progressive demise of dopaminergic neurons in the substantia nigra $(\mathrm{SN})$, inherited mutations underlying familial forms have provided insight into the molecular mechanisms of disease pathogenesis $[1,3]$. Oxidative stress, neuroinflammation, mitochondrial dysfunction, aberrant protein aggregation, excitotoxicity, and alterations in the autophagic-lysosomal pathway are implicated in the development and progression of PD [4-6]. PD also seems to have a mitochondrial component, so events that would modulate normal mitochondrial functions may compromise neuronal survival.

Nuclear factor E2-related factor 2 (Nrf2, NFE2L2) is a master regulator that induces a battery of cytoprotective genes including antioxidative enzymes, anti-inflammatory 
mediators, the proteasome, and several transcription factors involved in mitochondrial biogenesis. Thus, it may be a promising target to counteract mitochondrial dysfunction and its consequences in PD. Following its nuclear translocation, Nrf2 binds the antioxidant response elements (AREs) in the promoter region of its target genes. Several lines of evidence including in vivo Nrf2-deficient mouse studies, postmortem studies of PD brains, and genetic association studies of patients indicate a link between Nrf2 dysregulation and PD pathogenesis. Endogenous responses to upregulate Nrf2 and mitochondrial biogenesis in PD may be insufficient to prevent the progression of neurodegeneration. Thus, further activation of the Nrf2/ARE system using exogenous inducers may be a plausible therapeutic approach for PD.

This paper provides a brief overview of mitochondrial dynamics, mitochondrial dysfunction in $\mathrm{PD}$, and the Nrf2/ARE system. In addition, recent studies indicating a link between Nrf2 and PD are summarized. Finally, recent efforts employing inducers of $\mathrm{Nrf} 2$ activity to provide neuroprotection of nigral dopaminergic neurons in PD are emphasized.

\section{The Functions, Biogenesis, and Dysfunction of Mitochondria}

Mitochondria are membrane-enclosed organelles, which uniquely contain genetic material independent of nuclear DNA. These $1-10 \mu \mathrm{m}$ long cellular structures contain their own genome, which encodes tRNAs, rRNAs and 13 mitochondrial proteins $[7,8]$, while other components of the mitochondrial respiratory chain are encoded by the nuclear genome [9]. Multiple copies of the circular DNA are present in each mitochondrion. In humans, the size of the mitochondrial genome is $16,569 \mathrm{bp}$ and encodes for 2 ribosomal RNA molecules (16S and 12S rRNA) and 22 transfer RNA molecules $[9,10]$.

The structure of a mitochondrion includes outer membrane, intermembrane space, inner membrane, and matrix [8]. The topography of the inner membrane is complex and includes the electron transport system complexes, the adenosine triphosphate (ATP) synthetase complex, and transport proteins [11]. Mitochondria produce most of the cell's energy in the form of ATP through oxidative phosphorylation (OXPHOS). Depending on this process, there are five intramembrane complexes and two mobile electron carriers, called coenzyme $\mathrm{Q}$ and cytochrome $c$ [12]. Cytochrome $c$, which is an essential component of the electron transport chain, is located in the outer face of the inner membrane (intermembrane space) of the mitochondrion [13]. Cristae are structures that are formed by the folding of the inner membrane and provide increased surface area for chemical reactions, which take place in mitochondria [14].

Mitochondrial biogenesis is a process that involves interaction between the genetic systems of the organelle and the nucleus. During this process, mitochondria are newly formed in the cell. Many different signals can activate mitochondrial biogenesis. The main regulators of mitochondrial biogenesis include the peroxisome proliferator-activated receptor gamma coactivator (PGC) family of transcriptional activators, which consists of PGC- $1 \alpha$, PGC- $1 \beta$, and PGC-related coactivator (PRC) [15]. PGC- $1 \alpha$ plays a role in the activation of nuclear respiratory factor 2 and together they coactivate nuclear respiratory factor 1 . Consequently, nuclear respiratory factor 1 activates Tfam, which is important for mitochondrial DNA (mtDNA) transcription, translation, and repair. Thus, PGC-1 family coactivators act as mediators between the environment and the transcriptional machinery regulating the biogenesis of mitochondria [16].

Mitochondria also have roles in signaling, cellular differentiation, cell growth and cell death [17]. Dysfunction of the mitochondria is implicated in primary mitochondrial disorders, cardiac dysfunction, and the aging process. As one of the main sources of reactive oxygen species (ROS), these organelles can themselves be affected by oxidative damage, potentially membrane permeability transition, affecting the aging process and disease pathogenesis [18]. Oxidative damage to mitochondrial macromolecules can also transform into an apoptosis mechanism, which is the process of programmed cell death. Thus, many apoptotic responses occur in mitochondria which are altered in electron transport, the loss of membrane potential, the changes in oxidationreduction potential, the release of caspase regulators, and the attendance of pro- and anti-apoptotic Bcl-2 family proteins. Therefore, it is plausible that the effects of mitochondrial disruptions can play a role in human aging processes and degenerative diseases such as PD [19]. Sometimes, mitochondria containing a mutated genome are removed from the cell by mitophagy, a term for autophagy of the mitochondria [20].

\section{Mitochondrial Dysfunction in Parkinson's Disease}

The combination of mitochondrial dysfunction and increased oxidative stress are assumed to assist in the pathogenesis of PD [21]. Many lines of evidence suggest that mitochondrial dysfunction plays a central role in the pathogenesis of PD. The first observation in the early 1980s was that an inhibitor of complex I of the electron transport chain can induce parkinsonism. Moreover, mitochondria are targeted for the actions of parkinsonian neurotoxins such as 1-methyl-4-phenyl-1,2,3,6-tetrahydropyridine (MPTP), and its metabolite 1-methyl-4-phenylpyridinium $\left(\mathrm{MPP}^{+}\right)$, 6-hydroxydopamine (6-OHDA), rotenone, and paraquat $[22,23]$.

Deficiency in mitochondrial respiratory chain complex I and cristae disruption have been consistently described in PD [24]. It has been known that mitochondrial respiratory complex I (NADH-quinone oxidoreductase) activity declines in the SNpc of PD patients $[25,26]$. Moreover, the first transgenic mouse model for complex I deficiency has recently been generated. However, in this model, ATP levels were at the normal level, and oxygen consumption was not affected in NADH:ubiquinone oxidoreductase iron-sulfur protein 4 (NDUFS4) knocked-out mice. Furthermore, ROS formation in the neuronal cultures derived from those mice did not increase as was expected. It is clear that more in vivo 


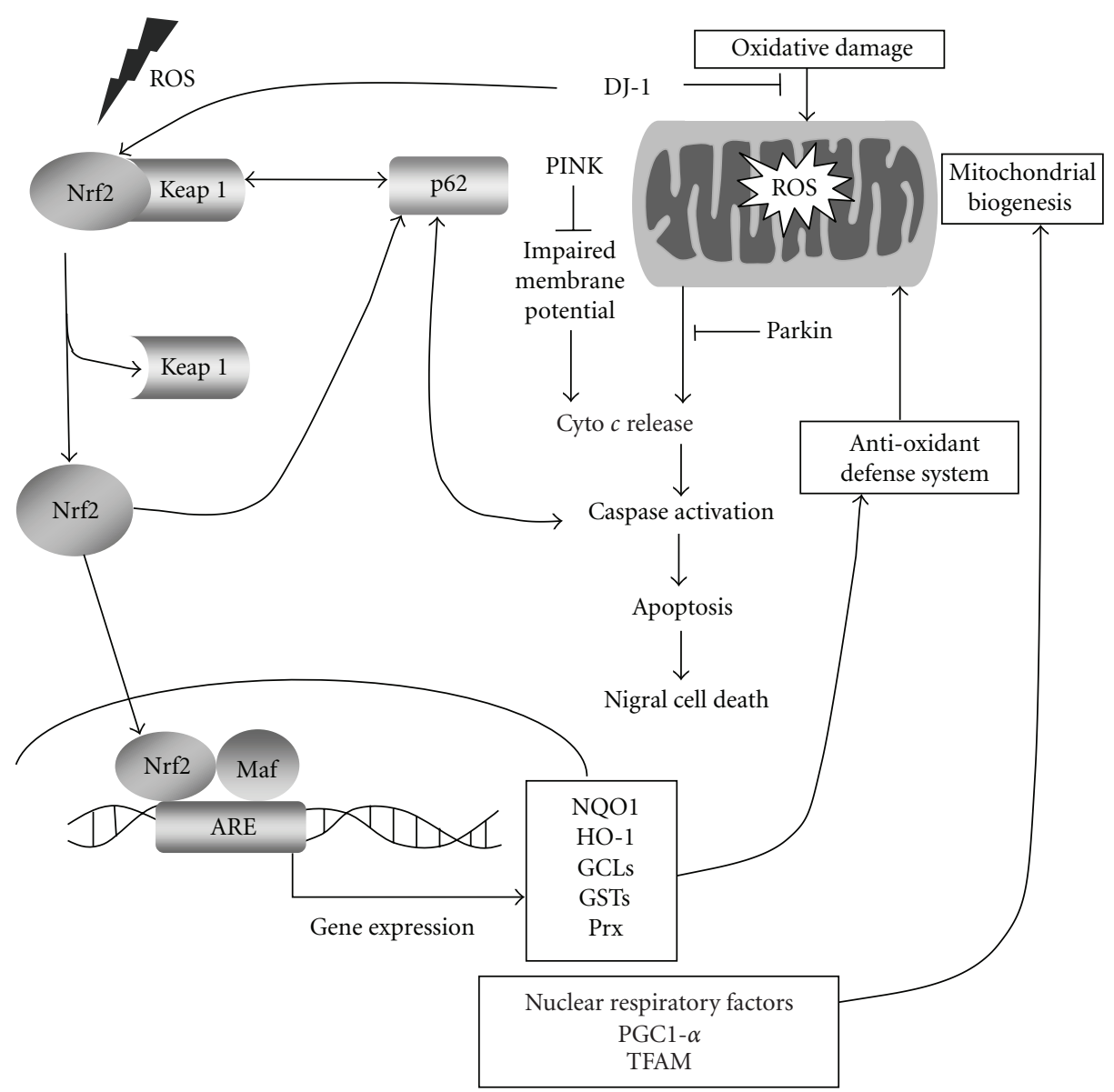

FIgURE 1: The role of the Nrf2 pathway in PD pathogenesis. In the case of oxidative damage, mitochondria produce increased amounts of ROS. Then, ROS activate Nrf2 bound to Keap1 in the cytoplasm, and it translocates into the nucleus to transactivate the transcription of ARE-bearing genes, which in turn activates the antioxidant defense system and mitochondrial biogenesis. In this pathway, PD-related genes are also involved. DJ-1 is found to inhibit oxidative damage in mitochondria. Another PD-related gene is PINK, which prevents impaired membrane potential of mitochondria and prevents apoptosis by counteracting cytochrome $c$ release that leads to apoptosis of nigral cells. Lastly, Parkin was found to inhibit cytochrome $c$ release that leads to caspase activation and apoptosis of nigral cells. Ubiquitin-interacting p62 also has a role in Nrf2 activation. It normally plays a role in transportation of ubiquitinated proteins to autophagosome. p62 was found to be interacting with Keap1 and transports it for autophagic degradation and provides indirect activation of Nrf2. p62 also has ARE in its promoter region which creates a positive feedback loop between Nrf2 and p62.

models are needed in order to explain the role of complex I deficiency in PD [27].

As in vivo evidence of mitochondrial dysfunction in PD, Hattingen et al. used a combination of anatomical magnetic resonance imaging and phosphorus and proton magnetic resonance spectroscopic imaging. They reported the presence of mitochondrial dysfunction of nigrostriatal dopaminergic neurons (see Figure 1). They also suggested that mitochondrial dysfunction phenomenon occurs in the early stages of PD pathogenesis [28].

mtDNA has an increased susceptibility to mutations because of less efficient DNA-repair mechanisms and the absence of protective histones. There are several clinical studies indicating a link between PD and specific mtDNA point mutations [29]. There is also a link between mtDNA and neurodegeneration, which was verified by genetic mouse models. Mitochondrial transcription factor A (Tfam) is a gene encoding the Tfam protein, which plays a role in promoters within the D-loop region of mtDNA and provides regulation of the transcription and replication [30]. Both nuclear respiratory factor 1 and nuclear respiratory factor 2 can adjust the expression of the Tfam gene by attaching to consensus-binding sites. When a conditional Tfam knockout mouse in midbrain dopaminergic neurons was generated, decreased mtDNA expression, respiratory chain deficiency, and neuronal cell death leading to staggered L-dopa-responsive impairment of motor functions were observed [31].

Remarkably, recent studies indicate that several PDassociated genes, directly or indirectly, impinge on mitochondrial integrity, thereby providing a specific link to the mitochondrial dysfunction observed in sporadic PD $[3,32]$. The protein products of PD genes, including alpha-synuclein, Parkin, PTEN-induced kinase 1 (PINK1), 
DJ-1, leucine-rich repeat kinase 2 (LRRK2) and HTR2A are localized to the mitochondria under certain conditions [33]. Functional studies in animal and cellular model systems have shown that PINK1 and Parkin play important roles in maintaining mitochondrial integrity and regulate mitochondrial morphology [3]. Loss-of-function mutations in the genes for these proteins are the primary cause of early-onset autosomal recessive forms of $\mathrm{PD}$ [1]. Parkin is an E3 ubiquitin-protein ligase, and impaired proteasome function has been described in sporadic PD. Parkin, therefore, promotes the degradation of dysfunctional mitochondria in cell culture conditions [34]. PINK1 represents the only kinase known to exhibit a canonical N-terminal mitochondrial localization signal [35]. These proteins are involved in mitophagy, the degradation process of terminally dysfunctional mitochondria in the lysosome [3, 32, 36]. Mutations in LRRK2 cause autosomaldominant familial PD. This kinase modulates vulnerability to mitochondrial dysfunction induced by neurotoxins [37]. Furthermore, DJ-1 localizes to mitochondria during oxidative stress, where it exhibits peroxiredoxin-like activity [38]. Mutations in DJ-1 render animals and cultured cells more susceptible to oxidative stress and mitochondrial toxins implicated in sporadic PD, lending support to the hypothesis that some PD cases may be caused by gene-environmental factor interactions $[39,40]$. A small proportion of alphasynuclein is imported into mitochondria, where it accumulates in the brains of PD patients and may impair respiratory complex I activity [41]. Alpha-synuclein binds to mitochondria and leads to mitochondrial fragmentation [42].

\section{The Nrf2/ARE Pathway}

In pathology of neurodegenerative disorders, the generation of ROS may be harmful affecting proteins, lipids, and nucleic acids [45]. ROS itself regulates redox homeostasis activating a group of genes and signal transduction pathways [46]. The Nrf2 pathway is one of the pathways that respond to ROS by activating the transcription of phase II detoxification enzymes [47]. It was first identified by Moi et al. in 1994, as controlling the expression of $\beta$-globin gene [47]. It belongs to the cap and collar family of transcription factors having a distinct basic leucine-zipper motif [48]. Nrf2 is found in the cytosol bound to its inhibitor kelch-like ECH-associated protein (Keap1). When redox balance is tipped toward the oxidative side, Nrf2 translocates into the nucleus and activates the transcription of ARE-containing genes [49]. During this activation, Keap1, which is sensitive to electrophilic and oxidative stimuli, regulates Nrf2 modification, holding Nrf2 in the cytosol along with actin filaments [50]. Unless it is activated, Nrf2 is ubiquitinated by the E3-ubiquitin ligase-like domain of Keap1, followed by $26 \mathrm{~S}$ proteasomal degradation [50]. Therefore, Keap1 regulates Nrf2 negatively, by promoting its sequestration and degradation.

$\mathrm{Nrf} 2$ is regulated by interactions between the conserved motifs DLG and ETGE within the Neh2 domain of Nrf2, the domain which regulates cellular stress responses, and the DGR region on Keap1. All of these domains provide correct positioning of Nrf2 for ubiquitination. When ROS accumulation increases in the cell, the binding to the DLG motif weakens; thus, ubiquitination is prevented [51-53]. In this way, degradation of $\mathrm{Nrf} 2$ decreases and stability of Nrf2 increases [43]. Extracellular signal-regulated kinase (ERK), c-Jun N-terminal protein kinase (JNK), and p38 mitogen-activated protein kinase (MAPK) pathways were shown to regulate $\mathrm{Nrf} 2$ transcriptional activity with an unknown mechanism. ERK and JNK appear to regulate positively the Nrf2 pathway after ARE-inducing substances, whereas p38 MAPK was reported to regulate Nrf2 both positively and negatively $[43,54]$. ERK, JNK, and p38 MAPK act by phosphorylating $\mathrm{N}$-terminal serine residues on $\mathrm{Nrf} 2$, which results as a response to electrophiles and oxidative stress [55]. Moreover, one of main signaling pathways, cytoprotective phosphotidylinositol-3 kinase (PI3K), which regulates maintenance of cellular homeostasis, was shown to regulate hemeoxygenase-1 (HO-1) under inflammatory stress [56]. Thus, it is proposed that the PI3K/Akt signaling pathway acts upstream of Nrf2 signaling. There are different upstream mechanisms, other than MAPK and PI3K/Akt, which are pancreatic endoplasmic reticulum kinase (PERK) and protein kinase $\mathrm{C}$ (PKC). In the case of redox imbalance, ROS can induce endoplasmic reticulum (ER) stress resulting in improper folding of proteins. There are different mechanisms to deal with this, one of which is PERK. Cullinan et al. found that Nrf2-target genes are activated in ER stress proposing PERK as the activator of Nrf2 [57]. Another Nrf2 mediator is PKC, which was first found by Huang et al. in 2000. As a result of inhibition experiments, they proposed that PKC is an upstream activator of Nrf2 signaling [58].

There are two hypotheses to explain the mechanism of Nrf2 translocation into the nucleus. According to the first hypothesis, there is nuclear localization signal in its basic region and two nuclear export signals in its leucine zipper and transactivation domain in order to provide Nrf2 nuclear translocation. In normal conditions, the nuclear localization signal is balanced by the nuclear export signal, and the sequestration of Nrf2 occurs in the cytosol. However, in stress conditions, the redox sensitive nuclear export signal found in the transactivation domain is disrupted. Thus, the nuclear localization signal drives translocation into the nucleus [59, 60]. However, this hypothesis fails to explain constitutive transcription of drug-metabolizing enzymes under normal conditions. For this reason, an alternative hypothesis was proposed. In this second hypothesis, Nrf2 is constitutively expressed and translocates into the nucleus. Its regulator and Keap1 enter into the nucleus by the CRM1/exportin pathway for removal and degradation of $\mathrm{Nrf} 2$, and after degradation it gets back into the cytosol. Consequently, under oxidative stress conditions, Nrf2 is expressed at the normal rate; however, its degradation rate decreases. In this way, its nuclear accumulation and transcriptional activity are enhanced $[61,62]$. In addition to the above hypotheses, a novel ubiquitin-binding protein, p62 (sequestosome 1, SQSTM1), was recently shown to activate Nrf2. Studies suggest that p62 interacts with the Keap1-binding site of Nrf2, resulting in activation and triggering of downstream events of the Nrf2 pathway $[63,64]$.

In cells, there are mechanisms to deal with oxidative stress, including phase II detoxification enzymes, which 
TABLE 1: Nrf2 target genes.

\begin{tabular}{|c|c|c|c|}
\hline Group & Gene symbol & Gene name & Function \\
\hline \multirow{7}{*}{ Glutathione homeostasis } & GSH & $\gamma$-glutamyl-cysteinyl-glycine & $\begin{array}{l}\text { Maintains redox } \\
\text { homeostasis during } \\
\text { oxidative stress }\end{array}$ \\
\hline & GST & Glutathione-S-transferase & Cellular detoxification \\
\hline & $\mathrm{Gcl}$ & Glutamate cysteine ligase & $\begin{array}{l}\text { Catalyzes glutathione } \\
\text { synthesis }\end{array}$ \\
\hline & Gcs & Glutamate cysteine synthetase & $\begin{array}{l}\text { Catalyzes glutathione } \\
\text { synthesis }\end{array}$ \\
\hline & GS & Glutathione synthetase & $\begin{array}{l}\text { Catalyzes glutathione } \\
\text { synthesis }\end{array}$ \\
\hline & GPx & Glutathione Peroxidase & $\begin{array}{l}\text { Catalyzes reduction of } \\
\mathrm{H}_{2} \mathrm{O}_{2} \text { or organic } \\
\text { hyperoxides to water }\end{array}$ \\
\hline & GR & Glutathione Reductase & $\begin{array}{l}\text { Catalyzes reduction of } \\
\text { oxidized GSSH to GSH }\end{array}$ \\
\hline \multirow{3}{*}{ Drug metabolism } & NQO-1 & $\begin{array}{l}\mathrm{NAD}(\mathrm{P}) \mathrm{H} \text { quinone } \\
\text { oxidoreductase-1 }\end{array}$ & $\begin{array}{l}\text { Catalyzes two-electron } \\
\text { reduction of quinones }\end{array}$ \\
\hline & Ugt & UDP-glucuronosyltransferases & $\begin{array}{l}\text { Catalyzes endogenous and } \\
\text { exogenous substances with } \\
\text { glucuronic acid }\end{array}$ \\
\hline & $\mathrm{mEH}$ & Microsomal epoxide hydrolase & $\begin{array}{l}\text { Inactivates epoxides } \\
\text { converting to vicinal } \\
\text { dihydrodiol }\end{array}$ \\
\hline \multirow{2}{*}{$\begin{array}{l}\text { Stress response proteins/iron } \\
\text { metabolism }\end{array}$} & Ferritin & Ferritin & $\begin{array}{l}\text { Iron binding protein having } \\
\text { role in iron oxidative stress }\end{array}$ \\
\hline & $\mathrm{HO}-1$ & Heme oxygenase- 1 & $\begin{array}{l}\text { Catalyzes oxidative cleavage } \\
\text { of Fe-protoporphyrin-IX }\end{array}$ \\
\hline \multirow{2}{*}{ Excretion/transporter } & Mdr & Multi-drug resistance protein & $\begin{array}{l}\text { Drug efflux pump for } \\
\text { xenobiotic compounds }\end{array}$ \\
\hline & Mrp & $\begin{array}{l}\text { Multidrug resistance } \\
\text { associated protein }\end{array}$ & $\begin{array}{l}\text { Multispecific organic anion } \\
\text { transporter }\end{array}$ \\
\hline \multirow{3}{*}{ Other genes metabolism } & G6PDH & $\begin{array}{l}\text { Glucose-6-phosphate } \\
\text { dehydrogenase }^{\mathrm{a}}\end{array}$ & Glycolysis \\
\hline & Taldo & Transaldolase $\mathrm{a}^{\mathrm{a}}$ & $\begin{array}{l}\text { Pentose phosphate pathway } \\
\text { enzyme }\end{array}$ \\
\hline & Tkt & Transketolase $^{\mathrm{a}}$ & $\begin{array}{l}\text { Channeling of excess } \\
\text { glucose phosphates to } \\
\text { glycolysis }\end{array}$ \\
\hline \multirow{4}{*}{ Immune system } & Pafah & PAF acetylhydrolase ${ }^{a}$ & $\begin{array}{l}\text { Catalyzes the degradation } \\
\text { of platelet-activating factor } \\
\text { to biologically inactive } \\
\text { products }\end{array}$ \\
\hline & Ptgs2 & $\begin{array}{l}\text { Prostaglandin-endoperoxide } \\
\text { synthase } 2^{\text {a }}\end{array}$ & Prostaglandin biosynthesis \\
\hline & Dig & $\begin{array}{l}\text { Dithiolethione-inducible } \\
\text { gene }^{\mathrm{a}}\end{array}$ & $\begin{array}{l}\text { Inhibition of chemically } \\
\text { induced tumorigenesis }\end{array}$ \\
\hline & Tac2 & Tachykinin $2^{\mathrm{a}}$ & Peptide neurotransmitter \\
\hline \multirow{4}{*}{ Calcium homeostasis } & Calb1 & Calbindin- $28 \mathrm{~K}^{\mathrm{b}}$ & Calcium binding protein \\
\hline & Syt1 & Synaptotagmin-1 $1^{\mathrm{b}}$ & Synaptic transmission \\
\hline & Hpca & Hippocalcin ${ }^{\mathrm{b}}$ & Calcium binding protein \\
\hline & S100A1 & $\begin{array}{l}\mathrm{S} 100 \text { calcium binding protein } \\
\mathrm{A} 1^{\mathrm{b}}\end{array}$ & Calcium binding protein \\
\hline
\end{tabular}


Table 1: Continued.

\begin{tabular}{|c|c|c|c|}
\hline Group & Gene symbol & Gene name & Function \\
\hline \multirow{4}{*}{ Growth factor } & Ngfg & Nerve growth factor- $\gamma^{\mathrm{b}}$ & $\begin{array}{l}\text { Growth factor for neuron } \\
\text { survival }\end{array}$ \\
\hline & FGF-13 & Fibroblast growth factor- $13^{\mathrm{b}}$ & $\begin{array}{l}\text { Nervous system } \\
\text { development and function }\end{array}$ \\
\hline & FGF-14 & Fibroblast growth factor- $14^{\mathrm{b}}$ & $\begin{array}{l}\text { Nervous system } \\
\text { development and function }\end{array}$ \\
\hline & BDNF & $\begin{array}{l}\text { Brain-derived neurotrophic } \\
\text { factor }^{b}\end{array}$ & $\begin{array}{l}\text { Growth factor for neuron } \\
\text { survival }\end{array}$ \\
\hline \multirow{5}{*}{ Intracellular signaling } & nGEF & Neuronal GEF ${ }^{\mathrm{b}}$ & $\begin{array}{l}\text { Intracellular signaling } \\
\text { networks }\end{array}$ \\
\hline & Prkcb & Protein Kinase C- $\beta^{\mathrm{b}}$ & Signal transduction \\
\hline & Gng3 & G-protein- $\gamma 3^{b}$ & Signal transduction \\
\hline & Adm & Adrenomedullin ${ }^{\mathrm{b}}$ & Adrenal development \\
\hline & Crh & $\begin{array}{l}\text { Corticotropin-releasing } \\
\text { hormone }^{\mathrm{b}}\end{array}$ & $\begin{array}{l}\text { Hormone released in } \\
\text { response to stress }\end{array}$ \\
\hline \multirow{4}{*}{ Neurotransmission/channel } & $\mathrm{Clcn}$ & Chloride channel $^{\mathrm{b}}$ & Ion channel protein \\
\hline & Gabr1 & GABA-A receptor- $1^{\mathrm{b}}$ & Neurotransmitter receptor \\
\hline & Gabrg3 & GABA-A receptor, gamma $3^{\mathrm{b}}$ & Neurotransmitter receptor \\
\hline & Gabbr1 & GABA-B receptor- $1^{\mathrm{b}}$ & Neurotransmitter receptor \\
\hline
\end{tabular}

Nrf2 activates a battery of ARE-driven genes, also known as classic Nrf2-target genes, which are classified into 4 groups as glutathione homeostasis, drug metabolism, stress-response protein/iron metabolism, and excretion/transporter [43]. In addition to classic genes, microarray experiments revealed cell-type specific target genes. From (a) primary astrocyte and (b) primary neuronal cultures, novel targets were identified [44]. They also are stated as other genes.

have ARE in its promoter or enhancer regions. According to genetic analyses, the ARE sequence is found in many genes, which play important roles in gene regulation [65, 66]. Nrf2 also interacts with the AP-1 family proteins Jun, Fos, and Maf. Maf binds to the maf recognition element (MARE), which is very similar to the core sequence of ARE [67-70]. However, maf proteins are reported to regulate ARE-containing genes negatively [69]. Furthermore, some maf genes, MafF, and MafG modulate the expression of ARE-containing genes [48]. Overexpression studies on Jun revealed that Jun acts as a positive regulator of the transcription of ARE-regulated genes. Moreover, according to the studies which unravel the relationship between Fos and Jun, it was concluded that Fos acts as negative regulator, in an opposite fashion to Jun [71].

Genes transcribed after Nrf2 activation are called the "Nrf2 regulon." This regulon performs several cellular functions, such as drug metabolism, ROS scavenging, glutathione homeostasis, efflux transport pathways, and activation of stress response proteins, which are vital for redox homeostasis $[61,72]$. In the last decade, the role of Nrf2 in disease pathogenesis and toxic insults was shown to be protective, and it is confirmed to be a multiorgan protector [44]. The Nrf2 regulon genes can be classified into various classes based on their functions: glutathione homeostasis, drug metabolism, stress-response protein or iron metabolism and excretion/transporter. The functions of each gene group and genes are summarized in Table 1. In some studies, microarray analysis of the Nrf2 regulon revealed more genes than classical ARE-containing genes by comparing expression patterns of neurons and astrocytes, which are indicated as other genes in Table 1 [44]. In addition to the genes listed in Table 1, we performed in silico transcription factor binding analysis using the JASPAR database by searching for ARE sequence in the promoter [73]. Novel Nrf2 targets were obtained, such as nuclear respiratory factor-1, Tfam, and peroxisome proliferator-activated receptor gamma coactivator 1 alpha (PGC1A). Nuclear respiratory factor-1 was experimentally validated to be a target gene for $\mathrm{Nrf} 2$ activation, which leads to mitochondrial biogenesis. In this way, apoptosis and necrosis can be prevented [74]. Peroxisome proliferatoractivated receptor gamma (PPAR- $\gamma$ ) is a protein that has many beneficial effects including anti-inflammation in multiple tissues. Cho et al. first showed the regulation of PPAP- $\gamma$ by Nrf2. They showed antioxidant effects of both Nrf2 and PPAR- $\gamma$, and they suggested that a PPAR- $\gamma$ agonist can be used to combat oxidative damage [75].

\section{The Nrf2/ARE Pathway and Parkinson's Disease}

Several lines of evidence suggest the involvement of the Nrf2/ARE pathway in the pathogenesis of PD. The first evidence came from a postmortem study that examined the expression and localization of $\mathrm{Nrf} 2$ in susceptible neuron populations in AD and PD brain tissues [76]. Ramsey et al. showed that in neurodegenerative diseases, Nrf2 expression is altered in both neurons and astrocytes. As compared with age-matched normal controls, nuclear Nrf2 staining was decreased in hippocampal CA1 neurons and surrounding glia in AD brains, whereas nuclear localization of $\mathrm{Nrf} 2$ was induced in $\mathrm{SN}$ in $\mathrm{PD}$ brains, even though the response 
appeared insufficient to protect neurons from degeneration. Consistent with the findings of the study by Ramsay et al., increased glutathione was found in PD patients, probably reflecting a response to oxidative damage [77]. Another study by Spencer et al. found decreased glutathione levels [78]. Since Nrf2 regulates several enzymes involved in glutathione synthesis, increased Nrf2 in surviving PD nigral neurons could be interpreted as an appropriate neuronal response to oxidative stimuli, even though the response appears insufficient to protect neurons from neurodegeneration. Similarly, in the MPTP model of PD, ARE-dependent gene expression was decreased in striatum whereas it increased in SN [79]. Because subcellular trafficking is critical to the activity of the Nrf2/ARE pathway, Ramsey et al. concluded that disrupted or insufficient ARE responses likely occur downstream of Nrf2 nuclear localization in PD [76]. Additional downstream mechanisms may interfere with ARE transactivation despite nuclear stabilization of Nrf2. Further investigation is needed to understand why Nrf2 nuclear translocation is not sufficient to prevent oxidative stress or ongoing neurodegeneration in SN. Ramsey et al. did not report increased nuclear Nrf2 staining in surrounding glia in $\mathrm{SN}$ in postmortem brains from PD individuals and questioned the necessity of astroglial $\mathrm{Nrf} 2$ activation in neuroprotection. In reduced in vitro cell culture systems, increased neuronal Nrf2 activation protects neurons from the oxidative insult induced by parkinsonian neurotoxins such as paraquat, 6-OHDA, $\mathrm{MPP}^{+}$, and rotenone even in the absence of astroglia [80-88].

Primary cell culture systems used in these studies typically utilize either neuronal cell lines or dissociated cells. Nevertheless, it is likely that increased Nrf2 activity in both neurons and glia contributes to neuronal survival in disease states. The glia-enriched and mixed neuronglia culture studies by Shih et al. suggest that in vitro neuroprotection against glutamate toxicity is not limited to increased neuronal Nrf2 activation, because activation of glial Nrf2 system also protects cultured neurons from insult [89]. A microarray analysis used to evaluate potential glial versus neuron-specific contributions to the neuroprotective effects of ARE activation and Nrf2 dependence showed that Nrf2 induction activates the expression of different genes in cultured astrocytes as compared with cultured cortical neurons. These results suggest that Nrf2-dependent genetic changes alter neuron-glia interactions resulting in neuroprotection [90]. The unique combination of cells found within organotypic nigrostriatal cocultures provides an ideal system by which we can examine this relationship between neurons and glia [91]. The neuroprotective effects of in vitro Nrf2 activation were also demonstrated in such organotypic nigrostriatal cocultures although the astroglial component was not studied [91]. All neurodegenerative diseases have different causes and mechanisms including progression, age of onset quality and severity of symptoms, survival after onset and cell population affected. Nrf2 was found to be regulated differently in neurons versus astrocytes [90]. Therefore, Ramsey et al. proposed that Nrf2 might regulate different gene products in various neuronal subpopulations (i.e., hippocampal neurons versus nigral neurons) [76].
Further studies are needed to explore how Nrf2 localization is regulated in a cell-type-specific manner, how it differs in various cellular populations and neuronal subpopulations, and how these differences may contribute to neuronal protection.

The link between the Nrf2/ARE pathway and PD was also studied using in vivo neurotoxin-based animal models of PD $[84,92]$. Nrf2 knockout mice display increased vulnerability to 6-OHDA, and the induction of the Nrf2/ARE pathway by transplantation of astrocytes overexpressing $\mathrm{Nrf2}$ can protect against 6-OHDA-induced damage in mouse brain [84]. Genetic deficiency of Nrf2 increases MPTP sensitivity in mice [79]. Furthermore, Nrf2 expression restricted to astrocytes is sufficient to protect against MPTP in transgenic mice with $\mathrm{Nrf2}$ under control of the astrocyte-specific promoter for the glial fibrillary acidic protein (GFAP)-Nrf2. These results show that astroglial modulation of the Nrf2/ARE pathway also plays a pivotal role in neuroprotection in vivo. According to the results of a very recent study based on the MPTP model, Nrf2 also modulates toxin-mediated activation of microglia, another glial cell type in the CNS [93]. Dopaminergic neurodegeneration and microglial activation induced by chronic injection of MPTP were more severe in Nrf2 knockout mice than in wild-type mice. Characteristic of classical microglial activation, the levels of proinflammatory cytokines interleukin-6 (IL-6) and tumor necrosis factoralpha (TNF- $\alpha$ ) and the enzymes inducible nitric oxide synthase (iNOS) and cyclooxygenase-2 (COX-2) were increased, while anti-inflammatory markers attributable to alternative microglial activation were decreased [94]. These results demonstrate a crucial role of Nrf2 in the modulation of microglial dynamics [93]. There may be crosstalk between glial cell subpopulations characterized by the modulation of the activation status of microglia by astroglia [95]. The astrocytes, the most abundant cells in the brain, can secrete one or more factors capable of modulating microglial activation by regulating microglial Nrf2 activation. Treatment of microglia with astrocyte culture-conditioned media induces the nuclear translocation of Nrf2 and enhanced HO-1 promoter activity in an ARE-dependent manner and increases the expression and activity of HO-1 in microglia. Furthermore, treatment with astrocyte culture-conditioned media suppresses Interferon-gamma- (IFN- $\gamma$-)induced ROS production, leading to reduced iNOS expression and nitric oxide (NO) release [95]. However, as demonstrated by a very recent in vivo study, HO-1 may not be involved in the neuroprotection elicited by $\mathrm{Nrf} 2$ in experimental parkinsonism [92]. Deficiency of HO-1 does not protect or enhance sensitivity to neuronal death, whereas Nrf2-knockout mice showed exacerbated gliosis and dopaminergic nigrostriatal degeneration in the MPTP model of PD $[96,97]$.

Genetic evidence indicating a link between Nrf2/ARE pathway and PD came from a recent study in which a complete haplotype analysis of the NFE2L2 and Keap1 genes in relation to the risk of PD was performed in two independent case-control materials [98]. A protective NFE2L2 haplotype was found in both European case-control materials. The molecular consequence of this haplotype may be increased efficiency in the Keap1-Nrf2-ARE response to 
oxidative stress and thereby higher capacity to withstand endogenous or environmental risk factors for PD. Genetic variation in Keap1 did not show any associations. These results together with recent preclinical data provide another link between oxidative stress and the pathogenesis of PD and support NFE2L2 as a novel susceptibility gene for PD [98].

The interaction of Nrf2 with a parkinsonian gene, DJ-1 (PARK7), may provide another link between Nrf2 function and PD. A recently discovered function of DJ-1 is to stabilize Nrf2 by preventing its interaction with Keap1 and Nrf2's subsequent ubiquitination [99]. Furthermore, protein expression of Nrf2 significantly decreases in paraquat-treated DJ1-deficient mice [100]. However, the findings of the study by Gan et al. using primary mouse embryonic fibroblasts were not confirmed in primary cortical neuronal and astrocyte cultures in vitro and ARE-driven human placental alkaline phosphatase (hPAP; ARE-hPAP) transgenic reporter mice in vivo [101]. Nrf2 activation, Nrf2-dependent gene induction, and Nrf2-mediated neuroprotection do not appear to be dependent on the presence of DJ-1 in the brain or in primary cultures derived from the brain. The most probable explanation for this discrepancy is the different cell types used in the two studies, suggesting that the relationship between DJ-1 and Nrf2 is cell-type specific. Neuroprotection by DJ-1 was confirmed in the second study [101].

Studies examining the Nrf2-activating effects of PD drugs support the link between the Nrf2/ARE pathway and PD. Apomorphine (Apo) is a drug used for clinical therapy of PD. It is a dopamine $\mathrm{D}(1) / \mathrm{D}(2)$ receptor agonist and has scavenger and protective effects in ROS-induced cell death. Hara et al. reported that Apo enhances protection in 6OHDA in vitro PD model in SH-SY5Y neuroblastoma cells. In that study, the involvement of the Nrf2 pathway in Apoenhanced protection was also investigated. They observed nuclear translocation of $\mathrm{Nrf} 2$ into the nucleus and induced the expression of HO-1 gene in a dose-dependent fashion. On the other hand, cotreatment of Apo with antioxidant $\mathrm{N}$ acetylcysteine suppressed the induction of HO-1 expression. Thus, Apo acts by producing intracellular ROS and activating the Nrf2 pathway to promote neuroprotective effects [81]. In addition to Apo, there is another cytoprotective drug, Deprenyl (Selegiline), that is, a promising candidate for neuroprotection, but its mode of action was unknown. However, Nakaso et al. reported a novel mechanism for the mode of action of Deprenyl, which involves PI3K and Nrf2 downstream oxidative-stress-related proteins. It increased the expression levels of HO-1, PrxI, TrxI, TrxRxI, gammaGCS, and p62/A170, induced Nrf2 nuclear accumulation, and increased the strength of Nrf2 binding to ARE site. Nrf2 activation led to the induction of PI3K-controlled antioxidant molecules, and TrkB was identified as the upstream element of the PI3K/Nrf2 mechanism. Thus, protective effects of Deprenyl depend on PI3K-Nrf2 activation, which switches the antioxidant mechanism leading to cytoprotection [63]. The latest clinically used PD drug is bromocriptine, which is a dopamine agonist. Not only does it normally improve motor deficits by dopamine D2 receptor activation, but it also has neuroprotective and antioxidant activities. As reported by Lim et al., bromocriptine upregulates $\mathrm{NAD}(\mathrm{P}) \mathrm{H}$ quinone oxidoreductase-1 (NQO1) expression and increases its activity, thus leading to the protection of PC12 rat adrenal pheochromocytoma cells against oxidative damage. Bromocriptine also increased Nrf2 expression and nuclear translocation. It is known that bromocriptine leads to cytoprotection and antioxidant effects via the PI3K/Akt pathway, but independent from dopamine receptor activation. Also, dopamine receptor D2 antagonist does not affect the cytoprotective effect of bromocriptine and Nrf2ARE activation by bromocriptine in dopamine D2 receptor expressing and nonexpressing cells. Consequently, NQO1 is a novel therapeutic target for $\mathrm{PD}$, which can be upregulated by PI3K and Nrf2 activation [102].

Specific links between Nrf2 function and PD have been revealed. The activity of Nrf2 decreases with aging [103, 104], the major risk factor for the development and progression of PD [105]. Dysregulation of the Nrf2/ARE pathway is seen in PD. Nrf2 activators including known antiparkinsonian drugs (deprenyl and apomorphine $[63,81]$ ) protect dopaminergic neurons against parkinsonian neurotoxins both in vitro and in vivo. Deficiency of Nrf2 aggravates experimental parkinsonism. Finally, apart from the stringent link between the Nrf2/ARE pathway and pathophysiological processes involved in PD such as oxidative stress, neuroinflammation, and ER stress, Nrf2 has the potential to interact with several molecules implicated in mitochondrial biogenesis (nuclear respiratory factors, PGC- $1 \alpha$, Tfam) and p62 which plays a role in mitophagy and the ubiquitin proteasome system (UPS) implicated in the pathogenesis of PD.

\section{Nrf2/ARE Pathway Activation as a Novel Therapeutic Approach to Mitochondrial Dysfunction in Parkinson's Disease}

As evidenced from postmortem tissue analyses and genetic analyses in humans and pathological studies in animal models, mitochondrial dysfunction plays a major role in PD, which leads to oxidative stress, DNA damage, and altered mitochondrial morphology and physiology. Therefore, therapeutic agents targeted to the mitochondria are thought to be promising tools for PD patients, such as agents targeting energy metabolism, mitochondria-targeted antioxidants, and more promising drugs that target the ARE/Nrf2/Keap1 pathway.

The Nrf2 pathway plays a role in redox homeostasis in cells. The main functions of $\mathrm{Nrf} 2$ were described in the previous part of this paper. The Nrf2 pathway is activated by ROS accumulation in cells; however, for therapuetic purposes, it is found to be activated by synthetic triterpenoids (TP), which are analogs of olenolic acid. They function as inhibitors of oxidative stress and cellular inflammatory processes and were shown to be protective in cancer models [106]. Moreover, the use of dietary compounds, synthetic chemicals, and xenobiotics decreases the incidence of diseases. For many decades, chemical substances from plants, called phytochemicals, have been shown to have chemopreventive activities, and most of them are suggested as Nrf2 inducers [107]. The potent chemopreventive compounds that induce Nrf2 can 
be listed as sulforaphane from cruciferous vegetables [108], curcumin [109], epigallocatechin-3-gallate from green tea [110], resveratrol from grape [111], caffeic acid phenethyl ester [109], wasabi [112], cafestol, kahweol [113], cinnamon based compounds [114], zerumbone [115], garlic organosulfur compounds [116], lycopene [117], carnosol [118], and avicins [119]. Novel compounds have been continuously discovered.

TPs are a group of Nrf2-activating compounds. Recently, novel Nrf2-activating, synthetic TP, CDDO methylamide (CDDO-MA), was tested by Yang et al. for neuroprotective effects in 3-nitropropionic acid (3-NP) rat and MPTP mouse models. CDDO-MA showed significant protection against both models and tert-butylhydroxyperoxide-induced ROS degeneration [120]. In addition to protective effects, CDDOMA upregulated the expression of genes involved in mitochondria biogenesis, glutathione synthesis, and antioxidant mechanisms. Thus, this compound was thought to be useful for the treatment of neurodegenerative diseases.

Other neuroprotective agents that induce the expression of hemeoxygenase-1 are electrophilic neurite outgrowthpromoting prostaglandin (NEPP) compounds [121]. NEPP compounds are cyclopentenone prostaglandin derivatives and function as neurotrophic factors. According to a report by Satoh et al., NEPPs were preferentially taken up into neurons, where they bind to Keap1 in a thiol-dependent fashion. They showed that NEPPs are neuroprotective in a glutamate excitotoxicity model in vitro and in a stroke model in vivo. They suggest that NEPPs activate the Keap1/Nrf2 pathway to modulate the prevention of excitotoxicity; therefore, they can be used as therapeutics in stroke and neurodegenerative diseases [122].

Shih et al. showed that dietary administration of Nrf2 inducer (tert-Butylhydroxyquinone) reduced susceptibility to 3-NP and increased striatal and cortical gamma-glutamylcysteinyl- glycine (GSH) levels in Nrf2-expressing mice but not in Nrf2-/-. These results suggested that Nrf2 inducers to be dietary administration may be alternative drugs for the treatment of neurodegenerative disorders [123].

Neuroprotective agents such as erythropoietin (Epo), which is known to pass the blood brain barrier [124], also exert Nrf2-activating effects. Epo provides neuroprotection in MPTP- and 6-OHDA-induced toxin models of PD [125, 126]. Recently, Epo has been found to activate Nrf2 in SH-SY5Y cells [127]. Epo induced Nrf2 translocation to the nucleus and upregulated the expression of the HO-1 gene. Also, MAPK and PI3K inhibitors caused decreased translocation of Nrf2 caused by Epo. These results suggest that Epo activates the Nrf2 pathway and the PI3K and MAPK pathways as well. It is interesting that Epo, which is reported as neuroprotective in PD animal models, triggers neuronal Nrf2 translocation. Thus, the neuroprotective effects of Epo can be mediated by Nrf2.

\section{Conclusions}

Mitochondrial dysfunction plays a central role in the pathogenesis of PD. For this reason, new therapeutic strategies in
PD targeting the restoration of mitochondrial dysfunction are being developed. The failure of antioxidant therapy strategies alone in clinical trials has encouraged efforts to find novel approaches strengthening endogenous antioxidant defense systems and inducing mitochondrial biogenesis and anti-inflammatory responses [123]. In this regard, Nrf2, a master regulator of the induction of a battery of genes affecting several cytoprotective systems, may be a promising target to counteract mitochondrial dysfunction and its consequences in PD. Thus, exogenous Nrf2 inducers should be tested for therapeutic potential in PD.

\section{Abbrevation}

\begin{tabular}{|c|c|}
\hline MPTP: & $\begin{array}{l}\text { 1-methyl-4-phenyl-1,2,3,6- } \\
\text { tetrahydropyridine }\end{array}$ \\
\hline $\mathrm{MPP}^{+}:$ & 1-methyl-4-phenylpyridinium \\
\hline 3-NP: & 3-nitropropionic acid \\
\hline 6-OHDA: & 6-hydroxydopamine \\
\hline ATP: & Adenosine triphosphate \\
\hline ARE: & Antioxidant response element \\
\hline Apo: & Apomorphine \\
\hline hPAP; ARE-hPAP: & $\begin{array}{l}\text { ARE-driven human placental } \\
\text { alkaline phosphatase }\end{array}$ \\
\hline CDDO-MA: & CDDO methylamide \\
\hline JNK: & c-Jun N-terminal protein kinase \\
\hline COX-2: & Cyclooxygenase- 2 \\
\hline Epo: & Erythropoietin \\
\hline ERK: & Extracellular signal-regulated kinase \\
\hline GSH: & Gamma-glutamiyl-cysteinyl- glycine \\
\hline GFAP: & Glial fibrillary acidic protein \\
\hline HO-1: & Hemeoxygenase-1 \\
\hline hPAP: & $\begin{array}{l}\text { Human placental alkaline } \\
\text { phosphatase }\end{array}$ \\
\hline iNOS: & Inducible nitric oxide synthase \\
\hline IFN- $\gamma:$ & Interferon-gamma \\
\hline IL-6: & Interleukin-6 \\
\hline Keap1: & Kelch-like ECH-associated protein \\
\hline LRRK2: & Leucine-rich repeat kinase 2 \\
\hline MARE: & Maf recognition element \\
\hline mtDNA: & Mitochondrial DNA \\
\hline MAPK: & Mitogen-activated protein kinase \\
\hline Tfam: & Mitochondrial transcription factor A \\
\hline NDUFS4 gene: & $\begin{array}{l}\text { NADH:ubiquinone oxidoreductase } \\
\text { iron-sulfur protein } 4\end{array}$ \\
\hline NADPH: & $\begin{array}{l}\text { Nicotinamide adenine dinucleotide } \\
\text { phosphate }\end{array}$ \\
\hline NQO1: & $\begin{array}{l}\text { NAD }(\mathrm{P}) \mathrm{H} \text { quinone } \\
\text { oxidoreductase- } 1\end{array}$ \\
\hline NEPP: & $\begin{array}{l}\text { Neurite outgrowth-promoting } \\
\text { prostaglandin }\end{array}$ \\
\hline NO: & Nitric oxide \\
\hline Nrf2: & Nuclear factor E2-related factor 2 \\
\hline OXPHOS: & Oxidative phosphorylation \\
\hline PD: & Parkinson's disease \\
\hline PPAR- $\gamma:$ & $\begin{array}{l}\text { Peroxisome proliferator-activated } \\
\text { receptor gamma }\end{array}$ \\
\hline PGC: & $\begin{array}{l}\text { Peroxisome proliferator-activated } \\
\text { receptor gamma coactivator }\end{array}$ \\
\hline
\end{tabular}


PGC1A: Peroxisome proliferator-activated receptor gamma coactivator 1 alpha

PRC: $\quad$ PGC-related coactivator

PINK1: PTEN-induced kinase 1

ROS: $\quad$ Reactive oxygen species

SQSTM1: Sequestosome 1

SN: $\quad$ Substantia nigra

Snpc: Substantia nigra pars compacta

TP: $\quad$ Triterpenoids

TNF- $\alpha$ : Tumor necrosis factor-alpha

UPS: Ubiquitin proteasome system.

\section{Acknowledgement}

The authors thank Professor Anne Frary for critical reading of the manuscript for English editing.

\section{Conflict of Interests}

The authors declare no competing financial interests.

\section{References}

[1] A. J. Lees, J. Hardy, and T. Revesz, "Parkinson's disease," The Lancet, vol. 373, no. 9680, pp. 2055-2066, 2009.

[2] H. Braak, U. Rüb, W. P. Gai, and K. Del Tredici, "Idiopathic Parkinson's disease: possible routes by which vulnerable neuronal types may be subject to neuroinvasion by an unknown pathogen," Journal of Neural Transmission, vol. 110, no. 5, pp. 517-536, 2003.

[3] E. Deas, N. W. Wood, and H. Plun-Favreau, "Mitophagy and Parkinson's disease: the PINK1-parkin link," Biochimica et Biophysica Acta. In press.

[4] A. Navarro and A. Boveris, "Brain mitochondrial dysfunction and oxidative damage in Parkinson's disease," Journal of Bioenergetics and Biomembranes, vol. 41, no. 6, pp. 517-521, 2009.

[5] M. E. Witte, J. J. G. Geurts, H. E. de Vries, P. van der Valk, and J. van Horssen, "Mitochondrial dysfunction: a potential link between neuroinflammation and neurodegeneration?" Mitochondrion, vol. 10, no. 5, pp. 411-418, 2010.

[6] M. Di Filippo, D. Chiasserini, A. Tozzi, B. Picconi, and P. Calabresi, "Mitochondria and the link between neuroinflammation and neurodegeneration," Journal of Alzheimer's Disease, vol. 20, supplement 2, pp. S369-S379, 2010.

[7] K. Henze and W. Martin, "Essence of mitochondria," Nature, vol. 426, no. 6963, pp. 127-128, 2003.

[8] B. Alberts, A. Johnson, J. Lewis et al., "Energy conversion: mitochondria and chloroplasts," in Molecular Biology of the Cell, pp. 815-827, Garland Science, Taylor \& Francis, Abington, UK, 2008.

[9] S. Anderson, A. T. Bankier, and B. G. Barrell, "Sequence and organization of the human mitochondrial genome," Nature, vol. 290, no. 5806, pp. 457-465, 1981.

[10] M. W. Gray, G. Burger, and B. F. Lang, "Mitochondrial evolution," Science, vol. 283, no. 5407, pp. 1476-1481, 1999.

[11] J. M. Herrmann and W. Neupert, "Protein transport into mitochondria," Current Opinion in Microbiology, vol. 3, no. 2, pp. 210-214, 2000.
[12] I. Wittig and H. Schägger, "Supramolecular organization of ATP synthase and respiratory chain in mitochondrial membranes," Biochimica et Biophysica Acta, vol. 1787, no. 6, pp. 672-680, 2009.

[13] J. E. Chipuk, L. Bouchier-Hayes, and D. R. Green, "Mitochondrial outer membrane permeabilization during apoptosis: the innocent bystander scenario," Cell Death and Differentiation, vol. 13, no. 8, pp. 1396-1402, 2006.

[14] T. G. Freya and C. A. Mannellab, "The internal structure of mitochondria," Trends in Biochemical Sciences, vol. 25, no. 7, pp. 319-324, 2000.

[15] J. Lin, C. Handschin, and B. M. Spiegelman, "Metabolic control through the PGC-1 family of transcription coactivators," Cell Metabolism, vol. 1, no. 6, pp. 361-370, 2005.

[16] R. C. Scarpulla, "Nuclear control of respiratory chain expression by nuclear respiratory factors and PGC-1-related coactivator," Annals of the New York Academy of Sciences, vol. 1147, pp. 321-334, 2008.

[17] H. M. McBride, M. Neuspiel, and S. Wasiak, "Mitochondria: more than just a powerhouse," Current Biology, vol. 16, no. 14, pp. R551-R560, 2006.

[18] S. Reddehase, B. Grumbt, W. Neupert, and K. Hell, "The disulfide relay system of mitochondria is required for the biogenesis of mitochondrial Ccs1 and Sod1," Journal of Molecular Biology, vol. 385, no. 2, pp. 331-338, 2009.

[19] D. C. Wallace, "Mitochondrial DNA mutations in disease and aging," Environmental and Molecular Mutagenesis, vol. 51, no. 5, pp. 440-450, 2010.

[20] R. Scherz-Shouval and Z. Elazar, "ROS, mitochondria and the regulation of autophagy," Trends in Cell Biology, vol. 17, no. 9, pp. 422-427, 2007.

[21] D. G. Nicholls and S. L. Budd, "Mitochondria and neuronal survival," Physiological Reviews, vol. 80, no. 1, pp. 315-360, 2000.

[22] R. Banerjee, A. A. Starkov, M. F. Beal, and B. Thomas, "Mitochondrial dysfunction in the limelight of Parkinson's disease pathogenesis," Biochimica et Biophysica Acta, vol. 1792, no. 7, pp. 651-663, 2009.

[23] K. F. Winklhofer and C. Haass, "Mitochondrial dysfunction in Parkinson's disease," Biochimica et Biophysica Acta, vol. 1802, no. 1, pp. 29-44, 2010.

[24] P. A. Trimmer, R. H. Swerdlow, J. K. Parks et al., "Abnormal mitochondrial morphology in sporadic Parkinson's and Alzheimer's disease cybrid cell lines," Experimental Neurology, vol. 162, no. 1, pp. 37-50, 2000.

[25] A. H. V. Schapira, J. M. Cooper, D. Dexter, P. Jenner, J. B. Clark, and C. D. Marsden, "Mitochondrial complex I deficiency in Parkinson's disease," Lancet, vol. 1, no. 8649, p. 1269, 1989.

[26] A. H. V. Schapira, J. M. Cooper, D. Dexter, J. B. Clark, P. Jenner, and C. D. Marsden, "Mitochondrial Complex I deficiency in Parkinson's disease," Journal of Neurochemistry, vol. 54, no. 3, pp. 823-827, 1990.

[27] W. S. Choi, S. E. Kruse, R. D. Palmiter, and Z. Xia, "Mitochondrial complex I inhibition is not required for dopaminergic neuron death induced by rotenone, MPP, or paraquat," Proceedings of the National Academy of Sciences of the United States of America, vol. 105, no. 39, pp. 1513615141, 2008.

[28] E. Hattingen, J. Magerkurth, U. Pilatus et al., "Phosphorus and proton magnetic resonance spectroscopy demonstrates mitochondrial dysfunction in early and advanced Parkinson's disease," Brain, vol. 132, no. 12, pp. 3285-3297, 2009. 
[29] A. K. Reeve, K. J. Krishnan, and D. Turnbull, "Mitochondrial DNA mutations in disease, aging, and neurodegeneration," Annals of the New York Academy of Sciences, vol. 1147, pp. 21-29, 2008.

[30] J. V. Virbasius and R. C. Scarpulla, "Activation of the human mitochondrial transcription factor A gene by nuclear respiratory factors: a potential regulatory link between nuclear and mitochondrial gene expression in organelle biogenesis," Proceedings of the National Academy of Sciences of the United States of America, vol. 91, no. 4, pp. 1309-1313, 1994.

[31] M. I. Ekstrand, M. Terzioglu, D. Galter et al., "Progressive parkinsonism in mice with respiratory-chain-deficient dopamine neurons," Proceedings of the National Academy of Sciences of the United States of America, vol. 104, no. 4, pp. 1325-1330, 2007.

[32] C. T. Chu, "Tickled PINK1: mitochondrial homeostasis and autophagy in recessive Parkinsonism," Biochimica et Biophysica Acta, vol. 1802, no. 1, pp. 20-28, 2010.

[33] D. M. Arduíno, A. R. Esteves, C. R. Oliveira, and S. M. Cardoso, "Mitochondrial metabolism modulation: a new therapeutic approach for Parkinson's disease," CNS and Neurological Disorders, vol. 9, no. 1, pp. 105-119, 2010.

[34] A. J. Whitworth and L. J. Pallanck, "The PINK1/Parkin pathway: a mitochondrial quality control system?” Journal of Bioenergetics and Biomembranes, vol. 41, no. 6, pp. 499-503, 2009.

[35] R. K. Dagda, J. Zhu, and C. T. Chu, "Mitochondrial kinases in Parkinson's disease: converging insights from neurotoxin and genetic models," Mitochondrion, vol. 9, no. 5, pp. 289$298,2009$.

[36] N. Matsuda and K. Tanaka, "Uncovering the roles of PINK1 and parkin in mitophagy," Autophagy, vol. 6, no. 7, pp. 952954, 2010.

[37] S. Saha, M. D. Guillily, A. Ferree et al., "LRRK2 modulates vulnerability to mitochondrial dysfunction in Caenorhabditis elegans," Journal of Neuroscience, vol. 29, no. 29, pp. 9210 9218, 2009.

[38] M. R. Cookson, "DJ-1, PINK1, and their effects on mitochondrial pathways," Movement Disorders, vol. 25, supplement 1, pp. S44-S48, 2010.

[39] I. Irrcher, H. Aleyasin, E. L. Seifert et al., "Loss of the Parkinson's disease-linked gene DJ-1 perturbs mitochondrial dynamics," Human Molecular Genetics, vol. 19, no. 19, pp. 3734-3746, 2010.

[40] L. Y. Hao, B. I. Giasson, and N. M. Bonini, "DJ-1 is critical for mitochondrial function and rescues PINK1 loss of function," Proceedings of the National Academy of Sciences of the United States of America, vol. 107, no. 21, pp. 9747-9752, 2010.

[41] H. Büeler, "Impaired mitochondrial dynamics and function in the pathogenesis of Parkinson's disease," Experimental Neurology, vol. 218, no. 2, pp. 235-246, 2009.

[42] F. Kamp, N. Exner, A. K. Lutz et al., "Inhibition of mitochondrial fusion by $\alpha$-synuclein is rescued by PINK1, Parkin and DJ-1," EMBO Journal, vol. 29, no. 20, pp. 35713589, 2010.

[43] S. Singh, S. Vrishni, B. K. Singh, I. Rahman, and P. Kakkar, "Nrf2-ARE stress response mechanism: a control point in oxidative stress-mediated dysfunctions and chronic inflammatory diseases," Free Radical Research, vol. 44, no. 11, pp. 1267-1288, 2010.

[44] J. M. Lee, J. Li, D. A. Johnson et al., "Nrf2, a multi-organ protector?” FASEB Journal, vol. 19, no. 9, pp. 1061-1066, 2005.
[45] M. Valko, C. J. Rhodes, J. Moncol, M. Izakovic, and M. Mazur, "Free radicals, metals and antioxidants in oxidative stress-induced cancer," Chemico-Biological Interactions, vol. 160, no. 1, pp. 1-40, 2006.

[46] T. Finkel, "Reactive oxygen species and signal transduction," IUBMB Life, vol. 52, no. 1-2, pp. 3-6, 2001.

[47] P. Moi, K. Chan, I. Asunis, A. Cao, and Y. W. Kan, "Isolation of NF-E2-related factor 2 (Nrf2), a NF-E2-like basic leucine zipper transcriptional activator that binds to the tandem NF-E2/AP1 repeat of the $\beta$-globin locus control region," Proceedings of the National Academy of Sciences of the United States of America, vol. 91, no. 21, pp. 9926-9930, 1994.

[48] H. Motohashi and M. Yamamoto, "Nrf2-Keap1 defines a physiologically important stress response mechanism," Trends in Molecular Medicine, vol. 10, no. 11, pp. 549-557, 2004.

[49] S. Dhakshinamoorthy and A. K. Jaiswal, "Functional characterization and role of INrf2 in antioxidant response element-mediated expression and antioxidant induction of $\mathrm{NAD}(\mathrm{P}) \mathrm{H}$ : quinone oxidoreductase1 gene," Oncogene, vol. 20, no. 29, pp. 3906-3917, 2001.

[50] T. W. Kensler, N. Wakabayashi, and S. Biswal, "Cell survival responses to environmental stresses via the Keap1-Nrf2-ARE pathway," Annual Review of Pharmacology and Toxicology, vol. 47, pp. 89-116, 2007.

[51] K. I. Tong, Y. Katoh, H. Kusunoki, K. Itoh, T. Tanaka, and M. Yamamoto, "Keap1 recruits Neh2 through binding to ETGE and DLG motifs: characterization of the two-site molecular recognition model," Molecular and Cellular Biology, vol. 26, no. 8, pp. 2887-2900, 2006.

[52] D. D. Zhang and M. Hannink, "Distinct cysteine residues in Keap1 are required for Keap1-dependent ubiquitination of Nrf2 and for stabilization of Nrf2 by chemopreventive agents and oxidative stress," Molecular and Cellular Biology, vol. 23, no. 22, pp. 8137-8151, 2003.

[53] A. Kobayashi, M. I. Kang, Y. Watai et al., "Oxidative and electrophilic stresses activate Nrf2 through inhibition of ubiquitination activity of Keap1," Molecular and Cellular Biology, vol. 26, no. 1, pp. 221-229, 2006.

[54] S. Naidu, V. Vijayan, S. Santoso, T. Kietzmann, and S. Immenschuh, "Inhibition and genetic deficiency of p38 MAPK up-regulates heme oxygenase-1 gene expression via Nrf2," Journal of Immunology, vol. 182, no. 11, pp. 70487057, 2009.

[55] H. C. Huang, T. Nguyen, and C. B. Pickett, "Phosphorylation of Nrf2 at Ser-40 by protein kinase C regulates antioxidant response element-mediated transcription," Journal of Biological Chemistry, vol. 277, no. 45, pp. 42769-42774, 2002.

[56] S. E. Pischke, Z. Zhou, R. Song et al., "Phosphatidylinositol 3-kinase/Akt pathway mediates heme oxygenase-1 regulation by lipopolysaccharide," Cellular and Molecular Biology, vol. 51, no. 5, pp. 461-470, 2005.

[57] S. B. Cullinan and J. A. Diehl, "PERK-dependent activation of Nrf2 contributes to redox homeostasis and cell survival following endoplasmic reticulum stress," Journal of Biological Chemistry, vol. 279, no. 19, pp. 20108-20117, 2004.

[58] H. C. Huang, T. Nguyen, and C. B. Pickett, "Regulation of the antioxidant response element by protein kinase C-mediated phosphorylation of NF-E2-related factor 2," Proceedings of the National Academy of Sciences of the United States of America, vol. 97, no. 23, pp. 12475-12480, 2000.

[59] A. K. Jain, D. A. Bloom, and A. K. Jaiswal, "Nuclear import and export signals in control of Nrf2," Journal of Biological Chemistry, vol. 280, no. 32, pp. 29158-29168, 2005. 
[60] W. Li, SI. W. Yu, and A. N. T. Kong, "Nrf2 possesses a redoxsensitive nuclear exporting signal in the Neh5 transactivation domain," Journal of Biological Chemistry, vol. 281, no. 37, pp. 27251-27263, 2006.

[61] T. Nguyen, P. J. Sherratt, P. Nioi, C. S. Yang, and C. B. Pickett, "Nrf2 controls constitutive and inducible expression of ARE-driven genes through a dynamic pathway involving nucleocytoplasmic shuttling by Keap1," Journal of Biological Chemistry, vol. 280, no. 37, pp. 32485-32492, 2005.

[62] J. A. Rubiolo, G. Mithieux, and F. V. Vega, "Resveratrol protects primary rat hepatocytes against oxidative stress damage: activation of the Nrf2 transcription factor and augmented activities of antioxidant enzymes," European Journal of Pharmacology, vol. 591, no. 1-3, pp. 66-72, 2008.

[63] K. Nakaso, C. Nakamura, H. Sato, K. Imamura, T. Takeshima, and K. Nakashima, "Novel cytoprotective mechanism of antiparkinsonian drug deprenyl: PI3K and Nrf2-derived induction of antioxidative proteins," Biochemical and Biophysical Research Communications, vol. 339, no. 3, pp. 915-922, 2006.

[64] M. Komatsu, H. Kurokawa, S. Waguri et al., "The selective autophagy substrate p62 activates the stress responsive transcription factor Nrf2 through inactivation of Keap1," Nature Cell Biology, vol. 12, no. 3, pp. 213-223, 2010.

[65] T. H. Rushmore, M. R. Morton, and C. B. Pickett, "The antioxidant responsive element: activation by oxidative stress and identification of the DNA consensus sequence required for functional activity," Journal of Biological Chemistry, vol. 266, no. 18, pp. 11632-11639, 1991.

[66] P. Nioi, M. McMahon, K. Itoh, M. Yamamoto, and J. D. Hayes, "Identification of a novel NRF2-regulated antioxidant response element (ARE) in the mouse $\mathrm{NAD}(\mathrm{P}) \mathrm{H}$ : quinone oxidoreductase 1 gene: reassessment of the ARE consensus sequence," Biochemical Journal, vol. 374, no. 2, pp. 337-348, 2003.

[67] R. Venugopal and A. K. Jaiswal, "Nrf2 and Nrf1 in association with Jun proteins regulate antioxidant response elementmediated expression and coordinated induction of genes encoding detoxifying enzymes," Oncogene, vol. 17, no. 24, pp. 3145-3156, 1998.

[68] K. Itoh, T. Chiba, S. Takahashi et al., "An Nrf2/small Maf heterodimer mediates the induction of phase II detoxifying enzyme genes through antioxidant response elements," Biochemical and Biophysical Research Communications, vol. 236, no. 2, pp. 313-322, 1997.

[69] T. Nguyen, H. C. Huang, and C. B. Pickett, "Transcriptional regulation of the antioxidant response element. Activation by Nrf2 and repression by MafK," Journal of Biological Chemistry, vol. 275, no. 20, pp. 15466-15473, 2000.

[70] M. Zhu and W. E. Fahl, "Functional characterization of transcription regulators that interact with the electrophile response element," Biochemical and Biophysical Research Communications, vol. 289, no. 1, pp. 212-219, 2001.

[71] T. Curran and B. R. Franza Jr., "Fos and jun: the AP-1 connection," Cell, vol. 55, no. 3, pp. 395-397, 1988.

[72] S. A. Reisman, D. B. Buckley, Y. Tanaka, and C. D. Klaassen, "CDDO-Im protects from acetaminophen hepatotoxicity through induction of Nrf2-dependent genes," Toxicology and Applied Pharmacology, vol. 236, no. 1, pp. 109-114, 2009.

[73] W. W. Wasserman and A. Sandelin, "Applied bioinformatics for the identification of regulatory elements," Nature Reviews Genetics, vol. 5, no. 4, pp. 276-287, 2004.

[74] C. A. Piantadosi, M. S. Carraway, A. Babiker, and H. B. Suliman, "Heme oxygenase-1 regulates cardiac mitochondrial biogenesis via nrf2-mediated transcriptional control of nuclear respiratory factor-1," Circulation Research, vol. 103, no. 11, pp. 1232-1240, 2008.

[75] H.-Y. Cho, W. Gladwell, X. Wang et al., "Nrf2-regulated PPAR $\gamma$ expression is critical to protection against acute lung injury in mice," American Journal of Respiratory and Critical Care Medicine, vol. 182, no. 2, pp. 170-182, 2010.

[76] C. P. Ramsey, C. A. Glass, M. B. Montgomery et al., "Expression of Nrf2 in neurodegenerative diseases," Journal of Neuropathology and Experimental Neurology, vol. 66, no. 1, pp. 75-85, 2007.

[77] M. Bogdanov, W. R. Matson, L. Wang et al., "Metabolomic profiling to develop blood biomarkers for Parkinson's disease," Brain, vol. 131, no. 2, pp. 389-396, 2008.

[78] J. P. E. Spencer, P. Jenner, and B. Halliwell, "Superoxidedependent depletion of reduced glutathione by L-DOPA and dopamine. Relevance to Parkinson's disease," NeuroReport, vol. 6, no. 11, pp. 1480-1484, 1995.

[79] P. C. Chen, M. R. Vargas, A. K. Pani et al., "Nrf2-mediated neuroprotection in the MPTP mouse model of Parkinson's disease: critical role for the astrocyte," Proceedings of the National Academy of Sciences of the United States of America, vol. 106, no. 8, pp. 2933-2938, 2009.

[80] M. Niso-Santano, R. A. González-Polo, J. M. Bravo-San Pedro et al., "Activation of apoptosis signal-regulating kinase 1 is a key factor in paraquat-induced cell death: modulation by the Nrf2/Trx axis," Free Radical Biology and Medicine, vol. 48, no. 10, pp. 1370-1381, 2010.

[81] H. Hara, M. Ohta, and T. Adachi, "Apomorphine protects against 6-hydroxydopamine-induced neuronal cell death through activation of the Nrf2-ARE pathway," Journal of Neuroscience Research, vol. 84, no. 4, pp. 860-866, 2006.

[82] Y. P. Hwang and H. G. Jeong, "The coffee diterpene kahweol induces heme oxygenase- 1 via the PI3K and p38/Nrf2 pathway to protect human dopaminergic neurons from 6hydroxydopamine-derived oxidative stress," FEBS Letters, vol. 582, no. 17, pp. 2655-2662, 2008.

[83] T. T. Cao, L. Ma, G. Kandpal, L. Warren, J. F. Hess, and G. R. Seabrook, "Increased nuclear factor-erythroid 2 p45-related factor 2 activity protects SH-SY5Y cells against oxidative damage," Journal of Neurochemistry, vol. 95, no. 2, pp. 406417, 2005.

[84] R. J. Jakel, J. A. Townsend, A. D. Kraft, and J. A. Johnson, "Nrf2-mediated protection against 6-hydroxydopamine," Brain Research, vol. 1144, no. 1, pp. 192-201, 2007.

[85] C. J. Wruck, M. Claussen, G. Fuhrmann et al., "Luteolin protects rat $\mathrm{PC} 12$ and $\mathrm{C} 6$ cells against $\mathrm{MPP}+$ induced toxicity via an ERK dependent Keap1-Nrf2-ARE pathway," Journal of Neural Transmission.Supplementum, vol. 72, pp. 57-67, 2007.

[86] J. M. Lee, A. Y. Shih, T. H. Murphy, and J. A. Johnson, "NFE2-related factor-2 mediates neuroprotection against mitochondrial complex I inhibitors and increased concentrations of intracellular calcium in primary cortical neurons," Journal of Biological Chemistry, vol. 278, no. 39, pp. 37948-37956, 2003.

[87] T. Satoh, N. Harada, T. Hosoya, K. Tohyama, M. Yamamoto, and K. Itoh, "Keap1/Nrf2 system regulates neuronal survival as revealed through study of keap1 gene-knockout mice," Biochemical and Biophysical Research Communications, vol. 380, no. 2, pp. 298-302, 2009.

[88] E. L. MacKenzie, P. D. Ray, and Y. Tsuji, "Role and regulation of ferritin $\mathrm{H}$ in rotenone-mediated mitochondrial oxidative stress," Free Radical Biology and Medicine, vol. 44, no. 9, pp. 1762-1771, 2008. 
[89] A. Y. Shih, D. A. Johnson, G. Wong et al., "Coordinate regulation of glutathione biosynthesis and release by Nrf2expressing glia potently protects neurons from oxidative stress," Journal of Neuroscience, vol. 23, no. 8, pp. 3394-3406, 2003.

[90] A. D. Kraft, D. A. Johnson, and J. A. Johnson, "Nuclear factor E2-related factor 2-dependent antioxidant response element activation by tert-butylhydroquinone and sulforaphane occurring preferentially in astrocytes conditions neurons against oxidative insult," Journal of Neuroscience, vol. 24, no. 5, pp. 1101-1112, 2004.

[91] A. Siebert, V. Desai, K. Chandrasekaran, G. Fiskum, and M. S. Jafri, "Nrf2 activators provide neuroprotection against 6hydroxydopamine toxicity in rat organotypic nigrostriatal cocultures," Journal of Neuroscience Research, vol. 87, no. 7, pp. 1659-1669, 2009.

[92] N. G. Innamorato, A. Jazwa, A. I. Rojo et al., "Different susceptibility to the parkinson's toxin MPTP in mice lacking the redox master regulator Nrf2 or its target gene heme oxygenase-1," PLoS One, vol. 5, no. 7, article e11838, 2010.

[93] A. I. Rojo, N. G. Innamorato, A. M. Martín-Moreno, M. L. De Ceballos, M. Yamamoto, and A. Cuadrado, "Nrf2 regulates microglial dynamics and neuroinflammation in experimental Parkinson's disease," Glia, vol. 58, no. 5, pp. 588-598, 2010.

[94] C. A. Colton, "Heterogeneity of microglial activation in the innate immune response in the brain," Journal of Neuroimmune Pharmacology, vol. 4, no. 4, pp. 399-418, 2009.

[95] K. J. Min, M. S. Yang, S. U. Kim, I. Jou, and E. H. Joe, "Astrocytes induce hemeoxygenase-1 expression in microglia: a feasible mechanism for preventing excessive brain inflammation," Journal of Neuroscience, vol. 26, no. 6, pp. 1880-1887, 2006.

[96] S. Marro, D. Chiabrando, E. Messana et al., "Heme controls ferroportin1 (FPN1) transcription involving Bach1, Nrf2 and a MARE/ARE sequence motif at position -7007 of the FPN1 promoter," Haematologica, vol. 95, no. 8, pp. 1261-1268, 2010.

[97] E. C. Pietsch, J. Y. Chan, F. M. Torti, and S. V. Torti, "Nrf2 mediates the induction of ferritin $\mathrm{H}$ in response to xenobiotics and cancer chemopreventive dithiolethiones," Journal of Biological Chemistry, vol. 278, no. 4, pp. 23612369, 2003.

[98] M. von Otter, S. Landgren, S. Nilsson et al., "Association of Nrf2-encoding NFE2L2 haplotypes with Parkinson's disease," BMC Medical Genetics, vol. 11, no. 1, Article ID 36, 2010.

[99] C. M. Clements, R. S. McNally, B. J. Conti, T. W. Mak, and J. P. Y. Ting, "DJ-1, a cancer- and Parkinson's diseaseassociated protein, stabilizes the antioxidant transcriptional master regulator Nrf2," Proceedings of the National Academy of Sciences of the United States of America, vol. 103, no. 41, pp. 15091-15096, 2006.

[100] W. Yang, L. Chen, Y. Ding, X. Zhuang, and U. J. Kang, "Paraquat induces dopaminergic dysfunction and proteasome impairment in DJ-1-deficient mice," Human Molecular Genetics, vol. 16, no. 23, pp. 2900-2910, 2007.

[101] LI. Gan, D. A. Johnson, and J. A. Johnson, "Keap1-Nrf2 activation in the presence and absence of DJ-1," European Journal of Neuroscience, vol. 31, no. 6, pp. 967-977, 2010.

[102] J. H. Lim, K. M. Kim, S. W. Kim, O. Hwang, and H. J. Choi, "Bromocriptine activates NQO1 via Nrf2-PI3K/Akt signaling: novel cytoprotective mechanism against oxidative damage," Pharmacological Research, vol. 57, no. 5, pp. 325331, 2008.

[103] W. Duan, R. Zhang, Y. Guo et al., "Nrf2 activity is lost in the spinal cord and its astrocytes of aged mice," In Vitro Cellular and Developmental Biology Animal, vol. 45, no. 7, pp. 388397, 2009.

[104] G. P. Sykiotis and D. Bohmann, "Stress-activated cap'n'collar transcription factors in aging and human disease," Science Signaling, vol. 3, no. 112, p. re3, 2010.

[105] J. V. Hindle, “Ageing, neurodegeneration and Parkinson's disease," Age and Ageing, vol. 39, no. 2, pp. 156-161, 2010.

[106] K. T. Liby, M. M. Yore, and M. B. Sporn, "Triterpenoids and rexinoids as multifunctional agents for the prevention and treatment of cancer," Nature Reviews Cancer, vol. 7, no. 5, pp. 357-369, 2007.

[107] A. Lau, N. F. Villeneuve, Z. Sun, P. K. Wong, and D. D. Zhang, "Dual roles of Nrf2 in cancer," Pharmacological Research, vol. 58, no. 5-6, pp. 262-270, 2008.

[108] T. W. Kensler, T. J. Curphey, Y. Maxiutenko, and B. D. Roebuck, "Chemoprotection by organosulfur inducers of phase 2 enzymes: dithiolethiones and dithiins," Drug Metabolism and Drug Interactions, vol. 17, no. 1-4, pp. 3-22, 2000.

[109] E. Balogun, M. Hoque, P. Gong et al., "Curcumin activates the haem oxygenase-1 gene via regulation of Nrf2 and the antioxidant-responsive element," Biochemical Journal, vol. 371, no. 3, pp. 887-895, 2003.

[110] H. K. Na and Y. J. Surh, "Modulation of Nrf2-mediated antioxidant and detoxifying enzyme induction by the green tea polyphenol EGCG," Food and Chemical Toxicology, vol. 46, no. 4, pp. 1271-1278, 2008.

[111] C. Y. Chen, J. H. Jang, M. H. Li, and Y. J. Surh, "Resveratrol upregulates heme oxygenase-1 expression via activation of NF-E2-related factor 2 in PC12 cells," Biochemical and Biophysical Research Communications, vol. 331, no. 4, pp. 993-1000, 2005.

[112] Y. Morimitsu, Y. Nakagawa, K. Hayashi et al., "A sulforaphane analogue that potently activates the Nrf2-dependent detoxification pathway," Journal of Biological Chemistry, vol. 277, no. 5, pp. 3456-3463, 2002.

[113] L. G. Higgins, C. Cavin, K. Itoh, M. Yamamoto, and J. D. Hayes, "Induction of cancer chemopreventive enzymes by coffee is mediated by transcription factor Nrf2. Evidence that the coffee-specific diterpenes cafestol and kahweol confer protection against acrolein," Toxicology and Applied Pharmacology, vol. 226, no. 3, pp. 328-337, 2008.

[114] B.-C. Liao, C.-W. Hsieh, Y.-C. Liu, T.-T. Tzeng, Y.-W. Sun, and B.-S. Wung, "Cinnamaldehyde inhibits the tumor necrosis factor- $\alpha$-induced expression of cell adhesion molecules in endothelial cells by suppressing NF- $\kappa \mathrm{B}$ activation: effects upon I $\kappa \mathrm{B}$ and Nrf2," Toxicology and Applied Pharmacology, vol. 229, no. 2, pp. 161-171, 2008.

[115] Y. Nakamura, C. Yoshida, A. Murakami, H. Ohigashi, T. Osawa, and K. Uchida, "Zerumbone, a tropical ginger sesquiterpene, activates phase II drug metabolizing enzymes," FEBS Letters, vol. 572, no. 1-3, pp. 245-250, 2004.

[116] C. Chen, D. Pung, V. Leong et al., "Induction of detoxifying enzymes by garlic organosulfur compounds through transcription factor Nrf2: effect of chemical structure and stress signals," Free Radical Biology and Medicine, vol. 37, no. 10, pp. 1578-1590, 2004. 
[117] A. Ben-Dor, M. Steiner, L. Gheber et al., "Carotenoids activate the antioxidant response element transcription system," Molecular Cancer Therapeutics, vol. 4, no. 1, pp. 177-186, 2005.

[118] T. Satoh, K. Kosaka, K. Itoh et al., "Carnosic acid, a catecholtype electrophilic compound, protects neurons both in vitro and in vivo through activation of the Keap1/Nrf2 pathway via S-alkylation of targeted cysteines on Keap1," Journal of Neurochemistry, vol. 104, no. 4, pp. 1116-1131, 2008.

[119] V. Handas, S.-O. Kim, G. Nishimura, A. Hausladen, J. S. Stamler, and J. U. Gutterman, "Avicinylation (thioesterification): a protein modification that can regulate the response to oxidative and nitrosative stress," Proceedings of the National Academy of Sciences of the United States of America, vol. 102, no. 29, pp. 10088-10093, 2005.

[120] L. Yang, N. Y. Calingasan, B. Thomas et al., "Neuroprotective effects of the triterpenoid, CDDO methyl amide, a potent inducer of Nrf2-mediated transcription," PLoS One, vol. 4, no. 6, article e5757, 2009.

[121] T. Satoh, K. Furuta, K. Tomokiyo et al., "Facilitatory roles of novel compounds designed from cyclopentenone prostaglandins on neurite outgrowth-promoting activities of nerve growth factor," Journal of Neurochemistry, vol. 75, no. 3, pp. 1092-1102, 2000.

[122] T. Satoh, S.-I. Okamoto, J. Cui et al., "Activation of the Keap1/Nrf2 pathway for neuroprotection by electrophillic phase II inducers," Proceedings of the National Academy of Sciences of the United States of America, vol. 103, no. 3, pp. 768-773, 2006.

[123] M. F. Beal, "Therapeutic approaches to mitochondrial dysfunction in Parkinson's disease," Parkinsonism and Related Disorders, vol. 15, supplement 3, pp. S189-S194, 2009.

[124] M. L. Brines, P. Ghezzi, S. Keenan et al., "Erythropoietin crosses the blood-brain barrier to protect against experimental brain injury," Proceedings of the National Academy of Sciences of the United States of America, vol. 97, no. 19, pp. 10526-10531, 2000.

[125] S. Genc, F. Kuralay, K. Genc et al., "Erythropoietin exerts neuroprotection in 1-methyl-4-phenyl-1,2,3,6tetrahydropyridine-treated C57/BL mice via increasing nitric oxide production," Neuroscience Letters, vol. 298, no. 2, pp. 139-141, 2001.

[126] A. P. Signore, Z. Weng, T. Hastings et al., "Erythropoietin protects against 6-hydroxydopamine-induced dopaminergic cell death," Journal of Neurochemistry, vol. 96, no. 2, pp. 428443, 2006.

[127] K. Genc, M. Y. Egrilmez, and S. Genc, "Erythropoietin induces nuclear translocation of Nrf2 and heme oxygenase-1 expression in SH-SY5Y cells," Cell Biochemistry and Function, vol. 28, no. 3, pp. 197-201, 2010. 


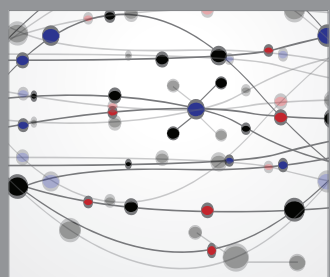

The Scientific World Journal
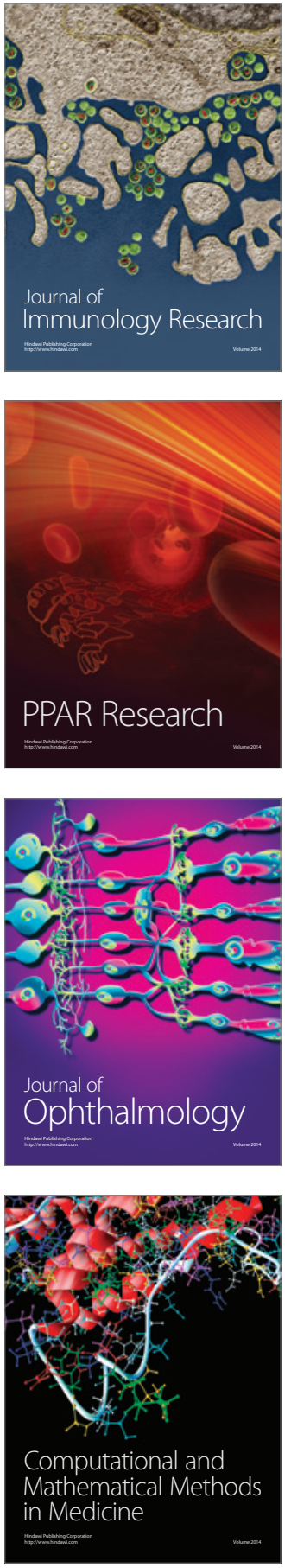

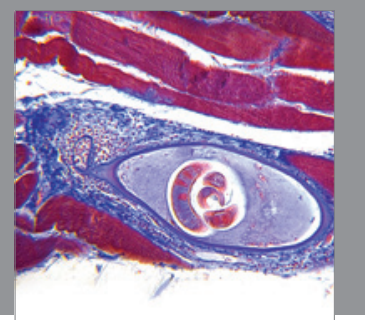

Gastroenterology

Research and Practice
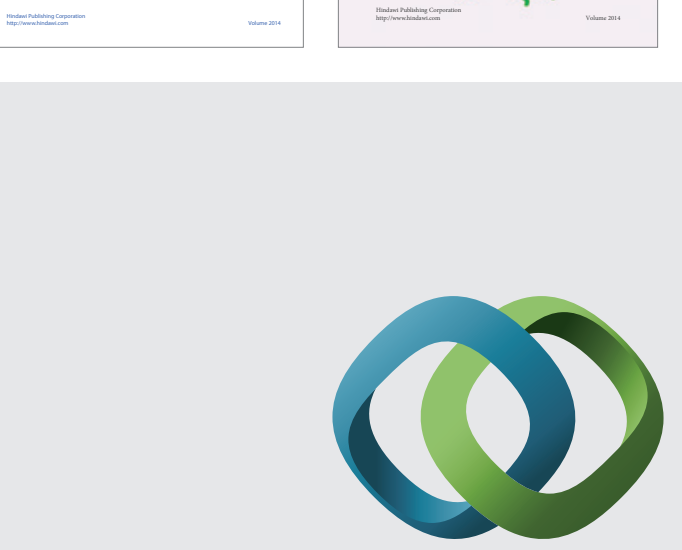

\section{Hindawi}

Submit your manuscripts at

http://www.hindawi.com
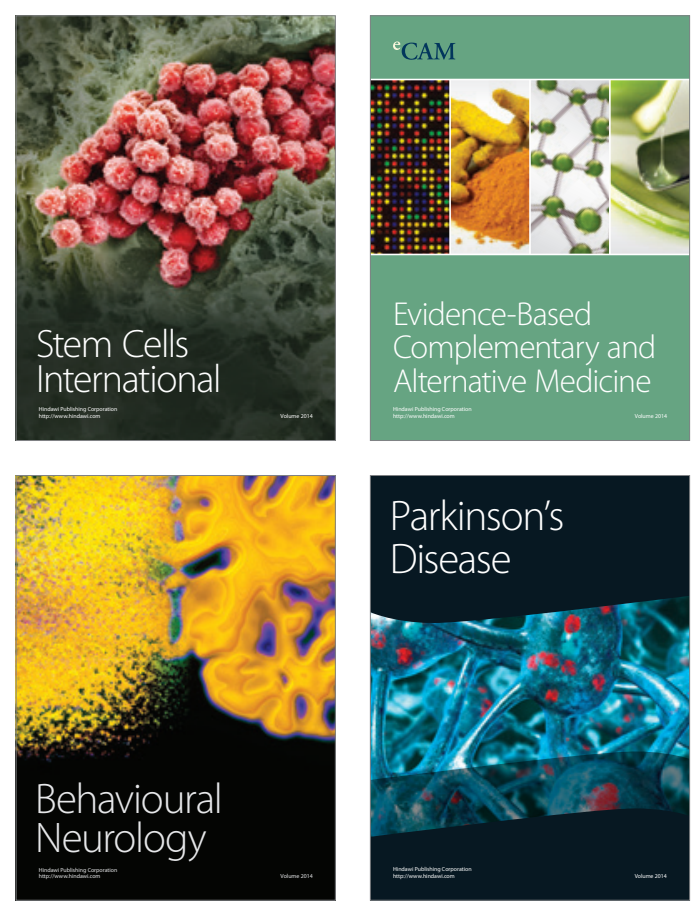

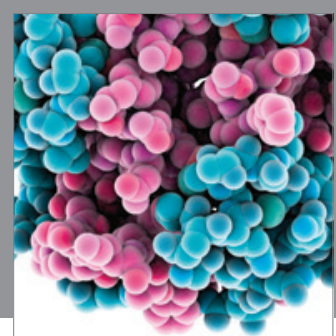

Journal of
Diabetes Research

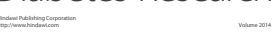

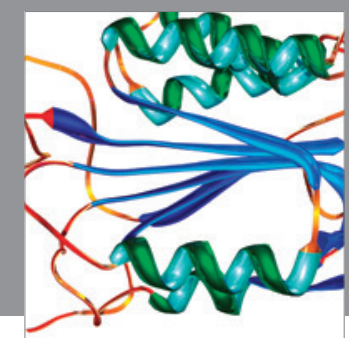

Disease Markers
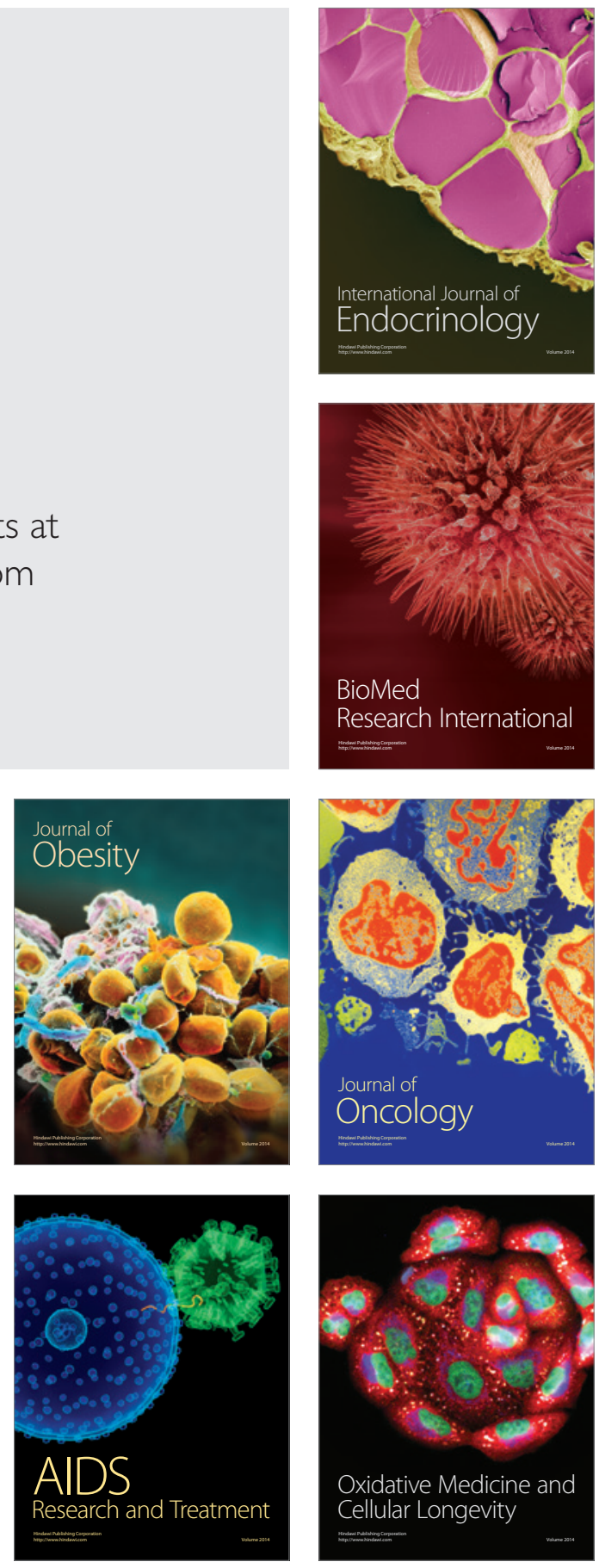